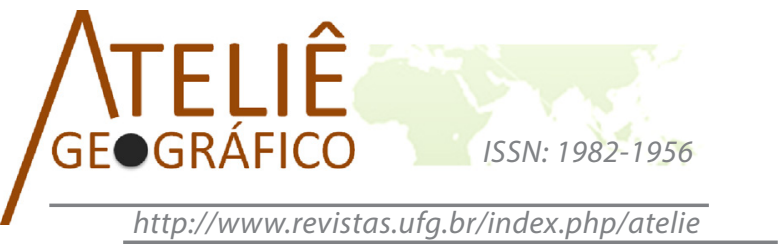

\section{A modernização da produção brasileira de coco e a racionalidade do capital}

\author{
The modernization of brazilian coconut production and the \\ capitalist rationality
}

\section{La modernisation de la production brésilienne de la noix de coco et la rationalite du capital}

\author{
Leandro Vieira Cavalcante \\ Universidade Estadual do Ceará \\ leandro.cavalcante@hotmail.com
}

\begin{abstract}
Resumo
Este artigo analisa o processo de modernização da produção brasileira de coco. $\mathrm{O}$ cultivo desse fruto vem sendo significativamente modificado nestas últimas décadas, quando se observa a passagem de um modelo de produção baseado no extrativismo para um modelo inserido em um contexto representado pelo advento da agricultura científica. Isso significa que a produção do fruto deixou de depender quase que exclusivamente de condicionantes naturais e passou a depender sobremaneira de insumos e implementos difundidos com a modernização agrícola, responsáveis por modificar as formas pelas quais o coco vinha sendo produzido até então, dotando-o de uma racionalidade anteriormente não observada.

Palavras-chave: Produção de coco; Modernização da agricultura; Reestruturação produtiva da agricultura.
\end{abstract}

\begin{abstract}
This article studies the process of modernization of Brazilian coconut production. The production of this fruit has been modified significantly in the last decades. In other words, the production model based on extraction has become into a scientific agriculture model. Thus, the fruit production is no longer dependent on natural factors and came to greatly depend on inputs and implements utilized with agricultural modernization, responsible for modifying the ways in which the coconut had been produced so far, giving it a rationality not previously observed.

Keywords: Coconut production; Agricultural modernization; Productive restructuring of agriculture.
\end{abstract}




\begin{abstract}
Résumé
Cet article analyse le processus de modernisation de la production brésilienne de la noix de coco. La culture de ce fruit a été modifiée de façon significative tout au long des dernières décennies, lorsque l'on observe le passage d'un modèle de production basé sur l'extractivisme vers un modèle inséré dans un contexte représenté par l'agriculture scientifique. Cela signifie que la production de ce fruit ne dépend presque plus de conditions naturelles et est venue à dépendre grandement sur les intrants et outils apparus après la modernisation agricole, responsables des changements considérables de la manière dont la noix de coco avait été produite jusqu' à nos jours.

Mots-clés: Production de la noix de coco; Modernisation de l'agriculture; Restructuration productive de l'agriculture.
\end{abstract}

\title{
Introdução
}

Sucessivos processos contribuíram, e ainda contribuem, para uma dinamização e reestruturação da produção agrícola brasileira, dotando-a de novas e importantes características, especialmente quando observamos os expressivos incrementos de tecnologia, ciência e informação, aliados a uma utilização cada vez mais intensa de capital e trabalho. Nota-se que a reestruturação produtiva da agricultura do país, e sua consequente modernização, é um processo ainda em curso, estendendo-se para inúmeros cultivos diferentes, modificando suas tradicionais formas de produção e trazendo significativos impactos socioespaciais, ambientais e territoriais. Esse é um dos retratos da atual organização da agricultura brasileira no período técnico-científico-informacional, segundo argumentam Elias (2003, 2007) e Santos e Silveira (2003).

Dentre os cultivos em que se observa uma modificação em seu sistema produtivo, especialmente através da sua modernização, destaca-se o cultivo de coco. O processo de produção desse fruto vem sendo significativamente modificado nessas últimas décadas, quando se percebe a passagem de um modelo de produção baseado no extrativismo para um modelo totalmente inserido em um contexto representado pelo advento da agricultura científica. Isso significa, entre outros motivos, que a produção do fruto deixou de depender essencialmente de condicionantes naturais e passou a depender sobremaneira de insumos e implementos difundidos com a modernização agrícola. Assim, sobretudo a partir de meados dos anos 1990, nota-se que a produção de coco passa a ser realizada também nos moldes dessa agricultura científica e inserida no contexto da agricultura de mercado, contrapondo-se a uma produção mais tradicional e de caráter de subsistência, que caracterizava praticamente todo setor até o final do século passado.

De um modo geral, percebe-se que o cultivo desse fruto deixa de ser realizado quase que exclusivamente por comunidades litorâneas localizadas na região Nordeste e em pequenas quantidades sem a utilização de quaisquer insumos, passando a ser cultivado em larga escala em todas as grandes regiões do país e a receber importantes aportes de capital, ciência e tecnologia, levando ao desenvolvimento de uma nova maneira de se produzir coco, ampliando a quantidade produzida e a produtividade. Infere-se que 
foi somente a partir da reestruturação produtiva pela qual passa o setor do coco que se puderam edificar as bases para uma verdadeira reviravolta no cultivo desse fruto no país, dotando-o de atributos até então não observados e inaugurando uma "nova geografia do coco", conforme explanado em Cavalcante (2012, 2014, 2015).

Com a reestruturação produtiva do setor do coco observa-se um intenso processo de modernização da produção do fruto, com uma substituição dos sistemas técnicos anteriormente utilizados e com a difusão de novos e modernos insumos, equipamentos e práticas agronômicas, responsáveis por modificar decisivamente as formas pelas quais o coco vinha até então sendo produzido, dotando o cultivo desse fruto de uma racionalidade anteriormente não observada, agora a serviço do aumento da produtividade do capital. Com isso, modifica-se assim não somente a forma como o coco passou a ser produzido, mas também os conteúdos técnicos do espaço e a organização das relações sociais de produção (SANTOS, 2009), haja vista que novos elementos passaram a fazer parte do universo que agora permeia o seu processo produtivo.

Nesse ínterim, o objetivo principal deste trabalho é, sobretudo, compreender o processo de modernização da produção brasileira de coco, ressaltando as modificações observadas no modo como esse fruto vem sendo produzido. Primeiramente discute-se a reestruturação produtiva da agricultura do país, responsável por lançar as bases para a modernização da produção de coco. Em seguida, é resgatado um pequeno histórico desse cultivo, indicando a passagem de um modelo de produção ancorado no extrativismo para um modelo alicerçado na agricultura científica. Apresenta-se ainda o atual contexto produtivo do coco no Brasil. Na sequência são ressaltados os processos de difusão de inovações técnico-científicas e agronômicas e de inserção da pesquisa agrícola no cultivo do fruto, evidenciando a modernização de sua produção. Por fim, é debatido quem passou a ter acesso a todas essas inovações, evidenciando o caráter conservador dos processos em curso.

Destaca-se que neste artigo são expostos apenas alguns dos resultados de uma investigação maior realizada a partir da consecução de nossa dissertação de mestrado (CAVALCANTE, 2015), e que por esse motivo muitas questões podem ficar em aberto, especialmente no que tange aos impactos negativos advindos da reestruturação e modernização da produção de coco, os quais não foram poucos. $\mathrm{O}$ propósito do artigo vai muito mais no sentido de apresentar o atual contexto produtivo do coco no Brasil, no intuito de fomentar o debate e o surgimento de novas questões, possibilitando avançar na própria investigação aqui exposta, sobretudo acerca dos problemas que podem decorrer da substituição da base técnica de uma determinada produção.

\section{A reestruturação produtiva da agricultura}

A agricultura brasileira conseguiu galgar outros patamares através do aumento de sua produtividade em virtude sobretudo de significativos investimentos em capital e tecnologia, realizados especialmente a partir de uma importante reestruturação produtiva do setor. Analisando esse processo, Elias $(2003,2006)$ considera que através dessa reestruturação produtiva da agricultura em curso desde meados dos anos 1970 foi possível 
intensificar o modo de produção capitalista no campo, além de modernizar a produção agrícola e de reorganizar as tradicionais formas de comercialização, distribuição e consumo. A autora destaca também que atualmente a agricultura brasileira não escapa da nova ordem econômica e se realiza de forma globalizada, "se não na sua produção propriamente, na sua circulação, distribuição ou seu consumo, mostrando-se uma das atividades mais contagiadas pela revolução tecnológica” (ELIAS, 2003, p. 59).

A reestruturação produtiva da agricultura, consoante assegura Elias (2003, 2006, 2007, 2013), caracteriza-se em especial pelos seguintes processos, entre outros: introdução de modernos insumos e implementos ao processo produtivo agrícola; readequação dos principais circuitos espaciais produtivos; consolidação de grandes empresas agrícolas e agroindustriais; integração de capitais comerciais, financeiros, industriais e agrícolas; reorganização do mercado de trabalho agrícola; surgimento de novos espaços especializados no desenvolvimento de uma agricultura científica e de mercado. Destaca-se que essa reestruturação atinge tanto a base técnica quanto a econômica e a social, exercendo profundos impactos sobre os espaços rurais do país, que passam por um acelerado processo de reorganização e mostram-se, em virtude disso, extremamente abertos à forma capitalista de produzir (ELIAS, 2006).

Elias (2003) considera que um dos principais fatores responsáveis pelo desencadeamento da reestruturação da agricultura nacional foi a mudança da base técnica do processo de produção agrícola, chamado por muitos de "modernização da agricultura". Essa mudança significa que a reprodução ampliada do setor agrícola passa a depender cada vez menos da dotação de recursos naturais utilizados como insumos e a sujeitar-se cada vez mais aos meios de produção gerados em setores especializados da indústria, contribuindo para ampliar a dependência da agricultura ao setor industrial (DELGADO, 1985). Além disso, infere-se que, para Martine (1991), não foi só a base técnica da produção agrícola que foi alterada em virtude da utilização intensiva em capital, mas também a composição dos produtos agrícolas e os processos de produção.

A esse respeito, Silva (2003) afirma que uma série de inovações responsáveis pela mudança da base técnica da produção do país passaram a adiantar substancialmente o processo produtivo agrícola, levando, dessa forma, a "um novo uso do tempo e um novo uso da terra" (SANTOS; SILVEIRA, 2003, p. 118). As inovações descritas por Silva (2003) são: as mecânicas, representadas por uma extensa gama de máquinas e equipamentos agrícolas, afetando particularmente a intensidade e o ritmo da jornada de trabalho; as físico-químicas, como toda uma série de adubos e fertilizantes, responsáveis por modificar as condições naturais da terra, elevando de forma considerável a sua produtividade; as biológicas (ou biotecnológicas), como as sementes híbridas e transgênicas, que seriam aquelas que afetam principalmente a velocidade de rotação do

\footnotetext{
1. É importante pontuar que os processos de "reestruturação produtiva da agricultura" e de "modernização da agricultura", apesar de complementares, retratam momentos diferentes e não devem ser entendidos enquanto sinônimos. A reestruturação produtiva da agricultura vai muito além de uma simples modernização do processo produtivo agrícola, com a substituição da base técnica aí utilizada, expandindo-se também para a comercialização, a distribuição e o consumo dos produtos, reorganizando o setor produtivo por inteiro, e não somente a atividade meramente agrícola.
} 
capital adiantado no processo produtivo; as agronômicas, que permitem basicamente a difusão de novos procedimentos e novos métodos de organização da produção.

A partir do advento dessas inovações, instala-se, para Santos (2003, p. 88), uma agricultura propriamente científica, responsável por mudanças profundas quanto à produção agrícola e quanto à vida de relações. Ainda segundo o autor, podemos falar de uma agricultura científica globalizada quando esta passa a ter uma referência planetária, recebendo influência das mesmas leis que regem os outros aspectos da produção econômica. Com o incremento da tecnologia, da ciência e da informação na agricultura cria-se um mundo rural onde "cada gesto e cada resultado deve ser previsto de modo a assegurar a maior produtividade e a maior rentabilidade possível" (SANTOS, 2009, p. 304), indispensáveis à reprodução do grande capital no campo.

Essa reestruturação da agricultura nacional ocasionou profundos impactos no espaço agrícola brasileiro, remodelando suas dinâmicas produtivas e socioespaciais. Conforme denotam estudos realizados por todo o país, nos espaços onde essa reestruturação do setor se materializa com mais intensidade notamos, além de outros processos, o acirrar das especializações produtivas, com a substituição de antigos cultivos, notadamente os voltados para a subsistência, por cultivos mais rentáveis e inseridos em uma agricultura de mercado. Observamos também a inserção cada vez maior de novos produtores nesse contexto, seja mediante a utilização do pacote técnico recém-difundido seja pela in/direta vinculação aos circuitos globalizados da produção e do consumo. Nota-se, ainda, o aumento do poderio de grandes empresas agrícolas e agroindustriais, instaladas principalmente nas regiões de expansão do modelo produtivo chamado de agronegócio.

Em linhas gerais, o movimento orquestrado no intuito de inserir a agricultura no contexto da reestruturação produtiva significou, antes de mais nada, a territorialização da racionalidade capitalista no campo, abrindo margem para o desenvolvimento do modelo do agronegócio e promovendo rebatimentos que atingiram seletivamente espaços, produtos e produtores com o único objetivo de ampliar o potencial agrícola do país e difundir a lógica de produção empresarial por todos os setores, tornando-os capazes de responder às exigências de um crescente mercado consumidor, seja ele interno e/ ou externo. A partir daí, e cada vez mais, as questões sobre o que, quando, como e onde produzir passaram a ser ações impostas aos produtores pelos agentes hegemônicos detentores de capital, transformando também o meio rural no espaço da racionalidade capitalista (SANTOS, 1996).

Essa reestruturação produtiva da agricultura brasileira, além de se processar de maneira espacialmente seletiva e socialmente excludente (ELIAS, 2006), vem privilegiando somente alguns gêneros agrícolas, que passam por uma modernização de seus processos produtivos e que são reorganizados com a finalidade de auferir uma maior rentabilidade ao capital, culminando em uma reconfiguração de seus circuitos espaciais de produção e círculos de cooperação (SANTOS, 1994, 1996), implicando novos usos do território, remodelando as dinâmicas socioespaciais precedentes e envolvendo uma quantidade cada vez maior de novos processos e agentes. Entre esses gêneros agrícolas 
que passaram a ter seus processos produtivos reestruturados destacam-se especialmente aqueles inseridos nos setores de grãos e da fruticultura, em que se inclui o coco.

De um modo geral, é em todo esse contexto que se insere a modernização da produção de coco no Brasil - processo esse diretamente influenciado por muitos dos mesmos processos que dinamizam o setor agrícola mundial e a economia brasileira como um todo. Assim, deve ficar claro que esse novo e atual momento de produção de coco não é algo que se dá de maneira isolada no contexto nacional, devendo ser entendido, portanto, como um desdobramento da reestruturação produtiva da agricultura brasileira, responsável por substituir a base técnica e as formas pelas quais o coco vinha sendo cultivado, contribuindo para inserir também esse fruto de maneira acirrada nos circuitos globalizados da produção e do consumo, controlados sobremodo por grandes empresas agrícolas, agroindustriais e de varejo.

\section{A evolução da produção de coco no Brasil}

A produção de coco no Brasil vem sendo historicamente realizada sobretudo no litoral da região Nordeste, em áreas sob o domínio do clima tropical e que apresentam solos arenosos. Foi nessa região onde o coqueiro, exclusivamente da variedade gigante, encontrou as condições ideais para se desenvolver. Foi também aí onde comunidades de camponeses encontraram no cultivo de coco uma de suas principais fontes de renda, contribuindo para a subsistência de suas famílias, servindo não apenas como alimento, mas também como fonte de renda com a venda do coco seco e como matéria-prima para a fabricação de utensílios domésticos, cobertura e revestimento de casas, construção de cercas e embarcações.

O coco, ao contrário do que se possa imaginar, não é um produto genuinamente brasileiro, e teve de ser importado de outros países até que a produção nacional se consolidasse, conforme indicam Siqueira et al. (2002). De acordo com esses autores, as primeiras mudas de coqueiro gigante foram introduzidas no país somente em 1553, pelos portugueses, quando houve o plantio de alguns coqueiros no atual Estado da Bahia, provavelmente oriundos da Índia ou do Sri Lanka. Como o cultivo do fruto foi inicialmente realizado no litoral nordestino, basicamente o baiano, até há bem pouco tempo falar em produção de coco no Brasil era o mesmo que falar em produção de coco no Nordeste, em razão da quase exclusiva concentração de coqueirais nessa região.

Essa produção de coco no Brasil pode ser subdividida em períodos passíveis de ser delimitados temporalmente. Assim, e de um modo geral, podemos subdividir a produção de coco no Brasil em quatro períodos distintos, tal qual propõem Costa e Gebara (2001) para o contexto mundial. Esses períodos, entendidos por Santos e Silveira (2003, p. 24) enquanto "pedaços de tempo definidos por características que interagem e asseguram o movimento do todo", revelam as especificidades do cultivo do fruto no decorrer da história e sobretudo como elas foram evoluindo. Destaca-se que esses quatro períodos não apresentam uma rigidez de datas e de características principais.

O primeiro período de produção de coco no Brasil, que vai de 1553 até meados de 1800 , é representado pela fase exclusivamente extrativista, quando apenas eram 
plantadas as árvores e colhidos os frutos dos coqueiros gigantes, sem a utilização de quaisquer instrumentos técnicos e/ou a realização de tratos culturais. Os coqueiros eram plantados de forma aleatória ao longo das faixas de praia, sem qualquer iniciativa voltada para a realização de um cultivo de caráter mais intensivo e menos extrativista. Além disso, nesse primeiro período foi importante o processo de adaptação das populações às potencialidades que poderiam ser usufruídas dos coqueiros, que, em um momento inicial, eram utilizados apenas para fornecer os frutos, consumidos in natura, isto é, não processados.

Num segundo período, que vai de 1800 até meados da década de 1930, houve uma considerável intervenção humana no processo produtivo do coco. Os coqueiros continuavam sendo produzidos ancorados em práticas extrativistas, mas com cultivos já realizados também em moldes semiextensivos, em que havia uma relativa preocupação com a produtividade das árvores, e os produtores já aplicavam adubos orgânicos e realizavam a poda dos coqueiros e a capina do local onde eles eram cultivados. A partir desse segundo período é que o cultivo de coco passa a adquirir um caráter voltado também para o mercado, ainda que fosse um mercado basicamente local e regional e ainda que o fruto continuasse a ser considerado enquanto uma atividade de subsistência, sendo comercializado apenas o seu excedente, conforme indicam Mota et al. (1995).

O terceiro período, que vai de meados de 1930 a 1990, marcou a consolidação do cultivo e do consumo de coco no Brasil. A produção do fruto já era reconhecida em todo o país por seu "intrínseco valor econômico", como se refere Pedrosa (1947), e o consumo de seus subprodutos, como o leite de coco e o coco ralado, anteriormente limitados apenas ao Nordeste, já havia se expandido para outras regiões. Iniciou-se também o desenvolvimento de uma produção voltada para atender o mercado nacional, motivada pelo aumento do consumo de coco e de seus subprodutos e pelo surgimento das primeiras grandes empresas agrícolas e agroindustriais do setor, especialmente a Sococo (fundada em 1966 em Alagoas) e a Ducoco (fundada em 1982 no Ceará), que são pioneiras no cultivo de variedades de coqueiros anões e híbridos, contribuindo para ampliar a produção de coco verde, por exemplo.

Andrade (1987, p. 87) destacava que ainda na década de 1970 o coqueiro era explorado "por grandes e médios proprietários que raramente limpa[va]m e aduba[va]m o coqueiral, limitando-se quase sempre a desfrutá-lo". E o autor acrescenta que somente a "racionalização da cultura poderia provocar aumento da produtividade, melhorando as condições econômicas dos proprietários e oferecendo maior produção". Mas é após o início dos anos 1980 que se observa uma relativa expansão da utilização de insumos químicos e orgânicos nos coqueiros, ligada à aplicação de pesticidas, ao desenvolvimento de sistemas de irrigação e à utilização de implementos agrícolas, associados a novas técnicas de cultivo.

Dessa forma, nota-se que a arquitetura do atual período da produção de coco no país foi traçada no decorrer das décadas de 1930 a 1990. Podemos entender esse período como o marco na transição entre dois distintos modelos produtivos, caracterizados por uma inserção cada vez maior da técnica, ciência e informação ao processo produtivo do coco, como visto no quarto e atual período, iniciado por volta de 1990. É somente nesse 
último período que há um crescimento considerável da produtividade das árvores, em virtude da disseminação de novas e modernas técnicas associadas ao processo produtivo do fruto. $\mathrm{O}$ grande diferencial desse quarto período vai ser justamente a utilização da ciência e da informação a serviço do cultivo de coco, em que a biotecnologia passa a assumir um papel importante.

Comprovando esse atual dinamismo, ao analisar os dados da evolução da produção de coco no Brasil (tabelas 01 e 02), nota-se que de 1990 a 2010 a quantidade produzida com o fruto obteve um aumento considerável, por volta de $158 \%$. A área plantada com coqueiros também acompanhou o aumento da produção do fruto, porém mais modestamente, tendo um crescimento de aproximadamente $28 \%$. Associada ao aumento da área plantada e da quantidade produzida, a produtividade também obteve um crescimento importante, duplicando em apenas 20 anos, pulando de três mil frutos por hectare ao ano para mais de seis, indicando uma modernização do processo produtivo do fruto. Ressalta-se, no entanto, a coexistência de outros fatores que ajudaram a alavancar a produção nacional, a exemplo da grande expansão do consumo de água de coco, que fez com que novos produtores passassem a investir no cultivo desse fruto.

Tabela 01. Brasil. Área plantada com coqueiros (em hectares), quantidade produzida de coco (em mil frutos) e produtividade (mil frutos/ha).

\begin{tabular}{l|c|c|c}
\hline & $\mathbf{1 9 9 0}$ & $\mathbf{2 0 0 0}$ & $\mathbf{2 0 1 0}$ \\
\hline Área plantada & 215.652 & 266.577 & 276.934 \\
Quant. produzida & 734.418 & 1.301 .411 & 1.895 .635 \\
Produtividade & 3,41 & 4,88 & 6,85 \\
\hline
\end{tabular}

Fonte: IBGE/PAM. Elaboração: Cavalcante, 2013.

Tabela 02. Brasil. Área plantada com coqueiros (em hectares), quantidade produzida de coco (em mil frutos) e produtividade (mil frutos/ha). Variações absoluta e relativa (em \%).

\begin{tabular}{l|ccc|ccc}
\hline & \multicolumn{3}{|c|}{ Variação Absoluta } & \multicolumn{3}{c}{ Variação Relativa } \\
\cline { 2 - 7 } & $\mathbf{1 9 9 0}-$ & $\mathbf{2 0 0 0 -}$ & $\mathbf{1 9 9 0}-$ & $\mathbf{1 9 9 0}-$ & $\mathbf{2 0 0 0}-$ & $\mathbf{1 9 9 0}-$ \\
& $\mathbf{2 0 0 0}$ & $\mathbf{2 0 1 0}$ & $\mathbf{2 0 1 0}$ & $\mathbf{2 0 0 0}$ & $\mathbf{2 0 1 0}$ & $\mathbf{2 0 1 0}$ \\
\hline Área plantada & 50.925 & 10.357 & 61.282 & 23,61 & 3,89 & 28,42 \\
Quant. produzida & 566.993 & 594.224 & 1.161 .217 & 77,20 & 43,57 & 158,11 \\
Produtividade & 1,48 & 1,96 & 3,44 & 43,35 & 40,21 & 101,00 \\
\hline
\end{tabular}

Fonte: IBGE/PAM. Elaboração: Cavalcante, 2013.

Deve-se atentar, todavia, para o fato de que esse atual período de produção de coco não se dá de maneira homogênea pelo país, pois apenas algumas parcelas do território nacional e alguns produtores foram inseridos nesse novo momento do cultivo do fruto, uma vez que, conforme ressaltam Santos e Silveira (2003, p. 140), "como em todos os períodos, o novo não é completamente difundido no território". Além disso, a emergência de um novo momento não elimina por completo as características do anterior, coexistindo, assim, diferentes períodos ao mesmo tempo. Isso pode ser notado, 
por exemplo, quando se observa a organização do modelo de produção ainda ancorada em práticas extensivas, representado pelo cultivo de coqueiro gigante, e a organização de um modelo produtivo intensivo, representado pelo cultivo das variedades de coqueiro anão e híbrido².

Assim, e de um modo geral, atualmente podemos perceber a coexistência de dois modelos produtivos completamente distintos no Brasil. Dessa forma, destaca-se que a reestruturação produtiva não atinge toda a produção de coco com a mesma intensidade, processando-se de maneira diferenciada quanto ao cultivo dessas diferentes variedades de coqueiro. Percebe-se que o cultivo de coqueiro gigante é o menos incorporado ao contexto da modernização produtiva, uma vez que, em geral, sua produção ainda se dá fortemente baseada em moldes extensivos e semiextensivos, com uma rarefeita utilização de inovações técnico-científicas e agronômicas, sem a realização de adubação, pulverização e irrigação.

Por outro lado, há uma expansão de áreas cultivadas com coqueiro anão e híbrido, que são a representação mais fiel da reestruturação produtiva em curso. Quando nos referimos ao contexto atual do fruto no Brasil estamos falando basicamente do cultivo dessas duas variedades, em ampla expansão por todo o território nacional, passando a ocupar até mesmo áreas não tradicionais no cultivo de coco, conforme indicam Fontes et al. (2002) e Martins e Jesus Júnior (2011). Motivados pelo aquecido mercado de coco verde no país, os produtores estão investindo cada vez mais no cultivo dessas variedades, segundo afirmam Cavalcanti, Mota e Silva (2006), ampliando o número de fazendas voltadas para a produção de coco e contribuindo também para um aumento da quantidade produzida com o fruto.

Dessa maneira, a modernização da produção de coco é uma realidade apenas para os cultivos de coqueiro anão e híbrido. Foram essas as variedades mais contagiadas pela reestruturação produtiva e as que mais absorveram as inovações advindas da agricultura científica. Além disso, infere-se que é também nas áreas de cultivo de coqueiro anão e híbrido onde o capital encontrou meios mais favoráveis de se difundir e de se territorializar, uma vez que foram essas as áreas elencadas pelo agronegócio para alavancar a quantidade produzida do fruto, impulsionada pelo aumento considerável do consumo de água de coco. O capital preferiu intencionalmente atuar no cultivo dessas duas variedades em detrimento do coqueiro gigante, visto que elas oportunizaram maiores retorno financeiro e renda.

\section{A modernização do processo produtivo do coco}

Elias (2003, p. 53) considera que a difusão de novos sistemas técnicos agrícolas contribui fortemente para uma reestruturação produtiva da agricultura, implicando em uma modernização do processo produtivo e em notáveis metamorfoses nas possibilidades de uso e ocupação do espaço agrícola. Nesse sentido, Aracri (2012)

2. Há três diferentes variedades de coqueiro: gigante (que apresenta árvores de maior porte e cujo foco é a produção de coco seco), anão (que apresenta árvores de menor porte e que normalmente são voltadas para a produção de coco verde) e híbrido (que é o cruzamento genético entre as variedades gigante e anã). 
assegura que a expansão horizontal (no espaço, com a incorporação de novas áreas) ou vertical (no tempo, com o aumento da produtividade) da agricultura não pode ocorrer sem uma consequente difusão de inovações técnicas pelo território. Em outras palavras, não há reestruturação produtiva da agricultura sem a incorporação de inovações, sem a introdução de modernos sistemas técnicos agrícolas ao processo produtivo, responsáveis por modernizá-lo.

Dentre as principais inovações técnicas associadas à produção de coco, o destaque vai principalmente para os novos métodos de irrigação que vêm sendo utilizados, a exemplo das práticas de irrigação localizada e totalmente automatizada, representada pelo uso dos microaspersores, onde cada coqueiro é irrigado individualmente e recebe uma quantidade exata de água. Esse método de irrigação por microaspersão é o mais utilizado atualmente pelos produtores de coco, sobretudo por aqueles que se dedicam ao cultivo de coqueiro anão e híbrido, visando a produção de coco verde para o consumo de água de coco. A irrigação localizada e automatizada vem revolucionando por completo a produção do fruto no Brasil.

Ressalta-se que até há bem pouco tempo os coqueiros não eram comumente irrigados, ou então eram irrigados por sistemas de sulco e/ou aspersão convencional, o que encarecia os gastos com água e mão de obra, além de não favorecer o aumento da produtividade. O desenvolvimento de uma agricultura irrigada na produção de coco, em detrimento da agricultura de sequeiro - ainda bastante comum no cultivo de coqueiro gigante -, representa, acima de tudo, uma intervenção direta do trabalho humano na busca por um aumento de produtividade, levando a uma considerável racionalização da atividade agrícola. Com a difusão do uso dos microaspersores, os produtores passaram a irrigar diariamente e ao mesmo tempo cada uma das árvores existentes na propriedade.

Além da utilização da irrigação, difunde-se o uso de uma série de agrotóxicos, adubos e fertilizantes dos mais variados tipos, sem os quais a produtividade dos coqueiros é bastante reduzida, segundo relatos dos produtores. Diretamente associada ao aumento do uso de microaspersores e à difusão de novos adubos e fertilizantes está a implementação da técnica de fertirrigação, que garante uma maior precisão, já que cada coqueiro vai receber uma quantidade predeterminada de fertilizantes diluídos na água aplicada pelos microaspersores. Com esse método, doses de nitrogênio e potássio diluídos em água são automaticamente aplicadas de modo individual a cada um dos coqueiros, proporcionando economia de fertilizantes, maior eficiência na sua aplicação e, consequentemente, aumento na produtividade e redução de custos.

Somada ao sistema de irrigação e insumos químicos e orgânicos, observa-se a difusão do uso de uma grande variedade de máquinas que servem de apoio à produção de coco. Esse maquinário agrícola é utilizado apenas no preparo do terreno e do solo, bem como na manutenção dos coqueirais, uma vez que o plantio e a colheita são atividades exclusivamente manuais. Os equipamentos mais utilizados pelos produtores do fruto são, entre outros: o arado (ou grade), usado para arar o solo antes do plantio dos coqueiros e também dos produtos que normalmente são cultivados entre as árvores; a roçadeira, bastante utilizada para fazer o controle das plantas que crescem em meio às linhas do coqueiral; o trator, empregado para puxar esses equipamentos e para transportar 
a produção de coco recém-colhida em caçambas. O uso desse maquinário agrícola é bastante recente e contribui sobremaneira para a redução do tempo de trabalho destinado ao trato dos coqueiros, modificando assim as relações de trabalho associadas ao cultivo de coco.

Cultivados atualmente de maneira intensiva, os coqueiros recebem cuidados constantes. Com isso, os chamados tratos culturais também foram readaptados às novas exigências do setor, difundindo-se uma série de inovações agronômicas que agem modificando as tradicionais formas de produção de coco. Além disso, todos os produtores que cultivam coqueiro anão e híbrido vêm adotando, sem exceção, um sistema de espaçamento entre as árvores conhecido como triangulação (Figura 01), indicado para melhor distribuir os coqueiros em uma determinada área, obedecendo-se uma distância mínima entre cada um deles, que normalmente varia entre 7 e 10 metros, dependendo do tamanho do estabelecimento, facilitando os tratos culturais e possibilitando a consorciação com outros cultivos. Essa padronização até mesmo da disposição das árvores no coqueiral é uma prova da racionalidade agora imposta ao cultivo de coco.

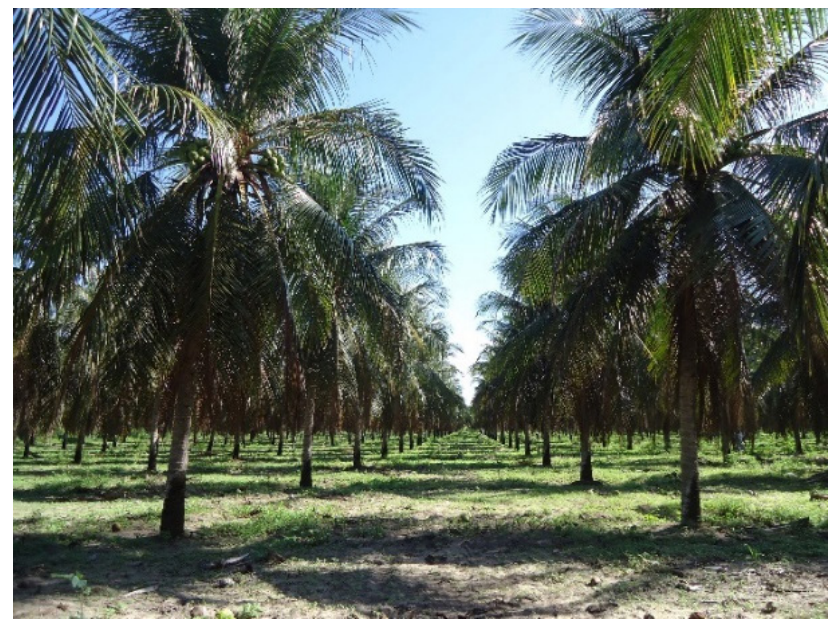

Figura 01. Padronização na disposição das árvores de coqueiro anão, em Paraipaba - Ceará. Fonte: Leandro Cavalcante, 2014.

Há também aqueles produtores, com mais recursos, que investem em análises foliar e de solo em laboratórios especializados, visando determinar as principais deficiências dos coqueiros e da área onde estão plantados; por vezes são os próprios produtores que fazem a coleta das folhas e de amostras de solo e as encaminham para esses laboratórios, que posteriormente enviam os resultados das análises via e-mail. Com isso, fica patente que a racionalidade do capital tornou necessária a existência de formas mais eficazes de produção, alterando radicalmente as forças produtivas da agricultura, "visto que seus conjuntos técnicos anteriormente hegemônicos não condiziam com a racionalidade vigente no período tecnológico" (ELIAS, 2003, p. 60). 
Um exemplo bastante elucidativo desse processo é o que é realizado, por exemplo, nas fazendas da Aurantiaca, holding de capital estadunidense e holandês instalada em 2006 no litoral norte baiano, já possuindo 6 mil hectares, com 230 mil coqueiros plantados. Utilizando um dos mais modernos sistemas de rastreabilidade do mundo, essa empresa investe pesado em agricultura de precisão. Além de ter todos os coqueiros irrigados por microaspersores e adubados via fertirrigação, uma das inovações implementadas pela Aurantiaca foi a numeração das árvores com uma placa contendo código de barras (Figura 02), onde mensalmente é registrada a quantidade de frutos colhidos, podendo-se assim mensurar e acompanhar a produtividade de cada coqueiro ao longo de vários anos.

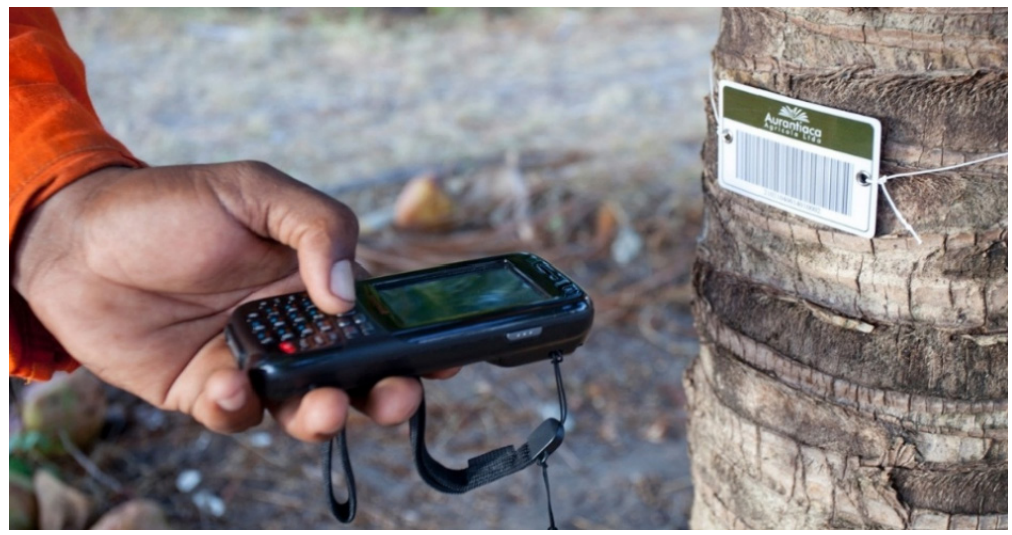

Figura 02. Coqueiro da empresa Aurantiaca com código de barras. Fonte: Portal UOL Economia, 2012. Disponível em: http://goo.gl/6IOfUv.

Todas as informações sobre quantidade produzida e sobre qualidades do solo e das árvores são enviadas para um banco de dados, e o conjunto dessas informações é utilizado para a criação de um mapa geral da fazenda, o que possibilita saber quais são os coqueiros mais produtivos e quais precisam de uma maior atenção técnica. Para o vicepresidente da Aurantiaca, em entrevista ao portal iBahia (http://goo.gl/01YjDO), esse é um exemplo claro de agricultura de precisão aplicada à produção de coco, o que ilustra, dessa forma, sua completa racionalização. $\mathrm{O}$ vice-presidente da empresa destaca ainda, nessa mesma entrevista, que, com a utilização dessa tecnologia associada à existência de código de barras nos coqueiros, o diferencial da Aurantiaca estaria centrado também na rastreabilidade e na certificação da produção. Para ele, a tecnologia utilizada na produção dos frutos vai colaborar também para conectar o produtor ao consumidor final, por meio da rastreabilidade do produto, possibilitando o conhecimento do processo produtivo do coco e servindo como forma de controle das atividades realizadas pelo trabalhador rural.

Outro exemplo dessa agricultura de precisão aplicada à produção de coco foi relatado pelo fundador/presidente da empresa Cohibra, uma das referências mundiais quando se fala de pesquisa voltada para o cultivo do fruto. Para ele, em entrevista a nós concedida, vivencia-se a partir de 2010 o segundo grande momento da modernização da 
produção de coco no país, representado pelo advento da agricultura de precisão, o grande diferencial do setor e o que coloca a produção do fruto no Brasil séculos à frente da realizada em inúmeros outros países pelo mundo. A Cohibra é uma das pioneiras nesse processo, que inclusive assessora e testa novas tecnologias em fazendas de empresas como a Aurantiaca. Ainda de acordo com o presidente da Cohibra, "A agricultura de precisão na produção de coco significa basicamente ter parâmetros precisos de controle de irrigação e nutrição. [...] Tudo é controlado e monitorado, do plantio das mudas à produção e colheita dos frutos".

O relato do presidente da Cohibra é um indicativo não só da racionalização do processo produtivo agrícola do coco, onde "tudo é controlado e monitorado", como ele próprio se refere, mas também de uma clara territorialização do capital no campo, uma vez que é esse capital que passa a controlar partes do processo produtivo, regulando até mesmo os processos de trabalho, como observado no depoimento do representante da Aurantiaca, ao salientar que a partir do rastreamento do coco qualquer pessoa pode ter acesso às informações do trabalhador que o cultivou, o que assegura um restrito controle de tudo o que ocorre no decorrer da produção do fruto. Infere-se que o advento dessa agricultura irrigada, intensiva e de precisão no cultivo de coco revela que estamos diante de uma agricultura essencialmente científica, sob o comando da racionalidade do capital.

\section{O papel da pesquisa agrícola na modernização da produção}

Boa parte dessas inovações só foi possível a partir de investimentos realizados no setor de pesquisa científica, um forte indutor da modernização da produção agrícola. Segundo Elias (2003), com a pesquisa científica foi possível reestruturar o conjunto de elementos técnicos empregados na agricultura, "transformando os tradicionais sistemas agrícolas e abrindo novas e inúmeras possibilidades à realização da mais-valia mundializada, por meio de um processo de fusão de capitais com os demais setores econômicos" (p. 60), e contribuindo sobremaneira para a racionalização da agricultura. Dessa forma, a ciência é colocada a serviço do capital, reforçando o controle do processo produtivo por aqueles que têm acesso aos resultados das pesquisas realizadas com vistas ao aumento de produtividade e à redução de custos, a exemplo do que também é observado na produção de coco.

De acordo com Costa e Gebara (2001), as pesquisas com coco no Brasil podem ser divididas em dois grandes momentos. O primeiro momento é marcado pelas tentativas de obtenção de novas variedades de coqueiro anão e por pesquisas que visavam maior eficiência na aquisição de mudas, mais resistentes e que apresentassem uma melhor produtividade, atividades essas realizadas por grandes produtores e agrônomos de maneira quase que individual. Já o segundo momento é marcado pela forte participação do Estado, com uma cerrada intervenção iniciada em meados da década de 1980, período em que a Embrapa (Empresa Brasileira de Pesquisa Agropecuária) começa a ter uma participação expressiva no que tange às pesquisas realizadas com coco, desenvolvendo uma série de experimentos e incorporando novas tecnologias ao processo produtivo. 
Ainda hoje a Embrapa é a principal empresa encarregada de realizar pesquisas com coco no Brasil, sobretudo as unidades Tabuleiros Costeiros e Agroindústria Tropical, liderando e coordenando a maior parte dos estudos acerca da produção de coco no país, desenvolvendo tecnologias e gerando novas informações que, quando repassadas aos produtores, contribuem para alavancar a produtividade dos coqueirais, aumentando a quantidade de frutos produzidos. A Embrapa Tabuleiros Costeiros se sobressai pela atuação direta do processo produtivo agrícola do coco, enquanto a Embrapa Agroindústria Tropical se distingue pelas pesquisas com um direcionamento maior para o processamento industrial do fruto. Consideramos essas duas unidades da Embrapa como alguns dos mais importantes agentes responsáveis pela reestruturação do setor de coco no Brasil, atuando diretamente na modernização dos processos produtivos agrícolas e, também, industriais.

A Embrapa Tabuleiros Costeiros, localizada em Aracaju (SE), em funcionamento desde 1993, foi originada a partir do Centro Nacional de Pesquisa de Coco (CNPCo), criado em 1985 e encarregado até então da coordenação de toda a pesquisa relacionada com o cultivo do fruto no Brasil, tornando-se ao longo de sua existência o maior e mais importante centro de pesquisa e difusão de tecnologia relacionada ao cultivo de coco do continente americano (MOTA et al., 1995). Hoje essa unidade da Embrapa é a mais especializada do país no que se refere à pesquisa no setor de produção de coco. A Tabuleiros Costeiros possui ainda um destaque internacional por abrigar o importante Banco Internacional de Germoplasma de Coco para a América Latina e Caribe, instalado em 2005 com o objetivo de organizar um banco de informações genéticas de diferentes variedades de coqueiro, originadas de diversas partes do mundo.

Já a Embrapa Agroindústria Tropical, localizada em Fortaleza (CE) e em funcionamento também desde 1993, foi originada do antigo Centro Nacional de Pesquisa de Caju e atualmente desenvolve estudos sobre vários produtos de origem tropical, entre eles o coco. Essa unidade conta com 12 laboratórios, e em alguns deles é realizada uma série de pesquisas com coco que colaboram para uma modernização e dinamização do setor, como, por exemplo: análises de eficiência da fertirrigação em coqueiros; manejos de irrigação; desenvolvimento de variedades de coqueiro híbrido; tratamento de póscolheita de coco verde; métodos de extração e envase de água de coco; conservação da água de coco por métodos combinados; reaproveitamento da casca de coco verde; fabricação de briquetes (carvão) com casca de coco; produção de nanocompositos e de placas de MDF a partir de fibras de coco.

Além das pesquisas de responsabilidade da Embrapa, merecem destaque também os estudos desenvolvidos pela Cohibra, empresa privada que concentra suas atividades no litoral do Ceará, no município de Amontada, e que começou suas pesquisas com o melhoramento genético de mudas de coqueiro em 1987, quando realizou o plantio de suas primeiras matrizes. Posteriormente, em 1995, iniciou a produção de mudas de coqueiro híbrido para fins comerciais, sendo atualmente a maior empresa de pesquisa, produção e venda de coqueiros híbridos do Brasil. A Cohibra é ainda a principal empresa privada do país que atua no ramo de pesquisa agrícola voltada para o cultivo de coco, possuindo também significativa relevância internacional. 
O carro-chefe da Cohibra é o desenvolvimento de tecnologias para a produção de mudas de coqueiro híbrido, geneticamente melhorado e apontado como mais resistentes às pragas. Nesse sentido, de acordo com Elias (2003), um dos avanços técnicos mais importantes conseguidos com a biotecnologia foi justamente a produção de híbridos, uma semente melhorada gerada em laboratório com a utilização da engenharia genética, "constituindo-se um dos principais signos da modernização da agricultura e um dos insumos industrializados mais utilizados no processo de mudança da sua base técnica" (ELIAS, 2003, p. 89). Destaca-se que a variedade de coqueiro híbrido foi a última a ser cultivada no Brasil e sua produção está em larga expansão por todo o país, motivada por empresas e grandes produtores sedentos por uma maior produtividade.

Outro órgão de grande relevância para a produção de coqueiro híbrido no país é o Centre de Coopération Internationale en Recherche Agronomique pour le Développement (CIRAD), da França, que atua no Brasil desde a década de 1970 em inúmeras pesquisas e projetos de extensão rural, entre eles o desenvolvimento de mudas dessa variedade de coqueiro. Fundado em 1984 após agregar centros de pesquisa agronômica franceses, o CIRAD é atualmente um dos maiores institutos de pesquisa agrícola do mundo, cujos estudos são realizados em mais de 90 países, inclusive no Brasil. O primeiro parceiro do CIRAD em nosso país no tocante à produção de coqueiros híbridos foi a empresa Sococo, que na década de 1980 realizou um grande plantio dessa variedade em suas fazendas do Pará. Além dessa empresa, o CIRAD atua também em constante parceria com a Embrapa e a Cohibra, aprimorando a engenharia genética aplicada à produção de coco.

A atuação dessas empresas citadas e as pesquisas por elas desenvolvidas foram fundamentais para modernizar o processo produtivo do coco e para impulsionar a reestruturação produtiva do setor. Essa introdução de inovações e da ciência na produção de coco mostrou-se, antes de mais nada, como uma necessidade real para a territorialização do grande capital no processo produtivo do fruto, já que as barreiras naturais que impediam o pleno desenvolvimento dessa produção tiveram de ser transpostas visando dotar esse cultivo de uma maior racionalidade capaz de levar ao aumento da produtividade das árvores (SILVA, 1998; ELIAS, 2003), elevando a produção de coco a outros patamares.

\section{$O$ acesso às inovações e à pesquisa agrícola}

Como visto, a modernização da produção de coco foi um dos principais processos advindos com a reestruturação produtiva do setor, responsável por modificar completamente o modo como esse fruto vinha sendo cultivado até então. A análise de como isso ocorre facilita sobremaneira a compreensão dos limites dessa reestruturação e do caráter conservador no qual ela se materializa nos espaços de produção do fruto e junto aos seus produtores, já que ela nos indica quem, de fato, passou a ter acesso a tudo o que a modernização proporcionou. Esse entendimento possibilita perceber ainda uma das maneiras encontradas pelo capital para se territorializar na produção de coco, já que, de acordo com Aracri (2012, p. 31), o processo de difusão de inovações impulsiona o "controle da produção e do território, subordinando o espaço agrário à lógica do capital industrial, porém com a indissociável colaboração dos capitais comerciais e, 
principalmente, financeiro". Dessa maneira, essa difusão de inovações pode ser entendida como uma forma de territorialização do capital, como também afirma Aracri (2012).

A partir de entrevistas realizadas com 66 produtores em seis municípios do litoral cearense, constatou-se que a maioria deles realizava praticamente os mesmos tratos culturais nos coqueiros e utilizavam basicamente os mesmos insumos e implementos agrícolas: o sistema de irrigação de grande parte deles é o de microaspersão, os coqueiros são adubados com produtos químicos e orgânicos a cada semestre e são pulverizados com agrotóxicos a cada mês, e a área do coqueiral é esporadicamente arada e gradeada. Entretanto, o modo como os produtores realizam essas atividades e o acesso que eles têm às inovações é que vão indicar de que maneira eles foram inseridos na modernização.

De um modo geral, verificou-se que a difusão do uso das inovações é observada principalmente entre os produtores que podem pagar para usufruir das suas benesses. Portanto, esse processo não se dá de maneira homogênea, revelando seu caráter conservador, que ao mesmo tempo em que inclui os detentores de capital e dos meios de produção exclui tantos outros, os quais, sem condições de ter acesso a todas as inovações advindas com a reestruturação produtiva, continuam à margem da dita modernização. A esse respeito, Alves (2001, p. 21) considera que "a grande maioria das tecnologias exige investimentos e capital de custeio de porte. Quem não tem recursos próprios ou acesso ao crédito [...] não tem como adotá-las". Notou-se que essa modernização da produção de coco só se efetiva concretamente para aqueles que podem pagar pelos novos serviços.

Por esse motivo, concorda-se com Alves (2001, p. 22) quando ele destaca que "as barreiras à entrada à inovação tecnológica geram um perfil dual na nossa agricultura, entre os que entraram no clube da agricultura moderna e os que estão fora dele. Se todos tivessem as mesmas oportunidades de acesso, nada haveria a objetar". A esse respeito, Frederico (2010, p. 129) assevera que a "implantação de objetos técnicos cada vez mais especializados promove uma seletividade dos agentes que detêm as informações necessárias para produzi-los e utilizá-los", e apenas os agentes com "maior acesso ao capital e à informação conseguem sobreviver [...]". Com a obrigatoriedade do uso sobretudo dos adubos e fertilizantes, os produtores são confrontados ainda com uma dependência do uso de tais insumos e, consequentemente, das empresas fabricantes e das lojas fornecedoras.

Além disso, após identificar os principais órgãos e empresas responsáveis pela realização de pesquisas com o coco, colaborando para o progresso técnico-científico do setor, cabe analisar quem é atendido por essas pesquisas e o seu real impacto. De imediato, é inegável a importância da agricultura científica para o desenvolvimento da produção de coco no país, entretanto não são todos os produtores que tiveram condições de ter acesso a pesquisas associadas ao cultivo do fruto. Assim, "faz-se necessário, portanto, tomar a ciência como produção ambígua, que se inscreve em uma sociedade mergulhada em contradições ditadas por interesses divergentes e inconciliáveis (...)" (PAULINO, 2006, p. 09).

Durante trabalhos de campo realizados no decorrer da pesquisa, quando perguntávamos aos produtores se eles tinham acesso a alguma pesquisa científica 
relacionada à produção de coco e/ou recebiam a visita de técnicos especializados, apenas os grandes produtores respondiam que sim, enquanto os pequenos afirmavam categoricamente que nunca ouviram falar sobre qualquer coisa do tipo, demonstrando que essas pesquisas e a assistência técnica não são difundidas a todos da mesma maneira. Isso vai de acordo com o que coloca Santos (2009, p. 243), ao afirmar que o conhecimento acaba "participando do clássico processo pelo qual, no sistema capitalista, os detentores de recursos competem vantajosamente com os que deles não dispõem".

Nesse sentido, analisando a atuação da Embrapa - não mais apenas enquanto produtora de conhecimento, mas também como difusora desse conhecimento - constatouse que esse órgão público não desempenha a função principal para a qual está designado, que seria promover o desenvolvimento integral da agricultura brasileira. Apesar da grande importância que a Embrapa teve (e ainda tem) para a reestruturação produtiva do setor do coco no Brasil, suas pesquisas não chegaram a todos, tendo sido usufruídas apenas por grandes produtores e empresas. Percebe-se, pois, que somente alguns poucos produtores têm acesso às pesquisas realizadas pela Embrapa, contratando seus serviços de consultoria ou entrando em contato com suas publicações.

O que foi observado no cultivo do coco corrobora a tese de que a pesquisa científica agrícola atua como um pilar da reprodução do capital no campo, já que ela é uma própria exigência desse capital. Para Silva (2003, p. 167), a pesquisa agrícola no Brasil fora orientada para atender "às novas e crescentes demandas dos setores industriais a montante e a jusante da produção agropecuária e se destinou a fortalecer o domínio do capital no campo". Ainda segundo esse autor, "o próprio sistema capitalista internalizou o processo de geração de conhecimento nos laboratórios das grandes empresas, das universidades e dos institutos de pesquisas. Com isso, o progresso tecnológico deixou de ser uma variável 'aleatória' [...]" (SILVA, 2003, p. 17).

Assim, fica evidente que o papel da ciência na modernização da produção de coco foi pensado e planejado visando atender interesses predeterminados, e que nem de longe coincidem com os anseios dos pequenos produtores, já que foi estruturado para responder aos interesses do grande capital. Dessa maneira, as evidências empíricas observadas durante os trabalhos de campo vão de acordo com o que já postularam vários autores, referindo-se ao caráter conservador da reestruturação da agricultura brasileira, a exemplo de Martine (1991), que mostrou que o pequeno produtor não foi, de modo algum, o grande beneficiado com a modernização agrícola. O que foi observado na produção de coco só reitera esse caráter conservador da chamada "modernização agrícola de prancheta" (MARTINS, 2014), que existe na teoria, mas que na prática se restringe a uns poucos espaços e produtores.

\section{Considerações finais}

A partir da análise da modernização da produção brasileira de coco, constatouse que nem esse fruto escapou da racionalidade imposta pelo capital, que viu aí apenas mais um ramo passível de ser expandido e reestruturado, o que vem ocorrendo sem muita dificuldade, com um objetivo claro de fomentar a reprodução ampliada do capital 
também nesse setor, que anteriormente se encontrava à margem do desenvolvimento de uma agricultura expressamente capitalista. E isso se dá em todo o setor agrícola de um modo geral, conforme assegura Santos (2009), ao pontuar que o campo modernizado é inserido em uma lógica competitiva que acelera a entrada da racionalidade do capital em todos os aspectos da atividade produtiva, uma vez que a "participação no mundo da competitividade leva ao aprofundamento das novas relações técnicas e das novas relações capitalistas" (p. 304).

Dessa forma, o setor produtivo do coco teve de ser reestruturado com a finalidade de fomentar a reprodução e a territorialização do capital. A partir de um certo momento, esse capital (e seus representantes, a exemplo das grandes empresas agrícolas e agroindustriais) decidiu que estava na hora de inserir o coco num circuito onde o único objetivo era auferir lucro a qualquer custo. A reestruturação desse setor apareceu, pois, como uma estratégia de sobrevivência desse capital, que, não mais vendo alternativas para a produção de coco seco, resolveu investir pesado na produção de coco verde e em tudo o que ela passou a representar. A esse respeito, Martins (1995, p. 160) destaca que a tendência do capital é de justamente "dominar tudo, subordinar todos os setores e ramos da produção e, pouco a pouco, ele o faz".

Além disso, com a modernização do processo produtivo do coco é latente a considerável ampliação das desigualdades entre os produtores do fruto, já que nem todos passaram a ter acesso de forma igualitária às inovações agora disponíveis. Observa-se também que uma parcela desses produtores não pôde sequer cogitar a possibilidade de adquirir tais inovações, correndo o risco de não conseguir garantir a sua permanência nessa atividade. Fora isso, enquanto anteriormente os coqueiros eram cultivados de forma extensiva, agora eles são altamente exigentes em capital e tecnologia, levando os produtores a ficarem cada vez mais dependentes dos insumos advindos da indústria e abrindo margem para acirrar ainda mais a territorialização do capital no setor.

$* * *$

Esse artigo é resultante de nossa pesquisa de mestrado financiada pelo Conselho Nacional de Desenvolvimento Científico e Tecnológico (CNPq) entre 2013 e 2015.

$* * *$

\section{Referências}

ALVES, Eliseu. Quem ganhou e quem perdeu com a modernização da agricultura brasileira. Revista de Economia e Sociologia Rural, São Paulo, v. 39, p. 09-39, 2001.

ANDRADE, Manuel Correia de. Geografia Econômica do Nordeste. O espaço e a economia nordestina. 4. ed. São Paulo: Editora Atlas, 1987.

ARACRI, Luís Ângelo. Reestruturação produtiva, território e difusão de inovações no campo: a agricultura de precisão em Mato Grosso. Rio de Janeiro: Arquimedes Edições, 2012. 
CAVALCANTE, Leandro Vieira. Os circuitos espaciais e os círculos de cooperação da produção de coco no Litoral Oeste do Ceará. 187 f. Monografia (Graduação em Geografia). Universidade Estadual do Ceará, Fortaleza, 2012.

CAVALCANTE, Leandro Vieira. La restructuration de la production de noix de coco au Brésil: enjeux et défis. Le cas des nouvelles dynamiques socio-spatiales du Périmètre Irrigué Curu-Paraipaba. 109 f. Mémoire de recherche (Master en Géographie). Université Paris 1 Panthéon Sorbonne, Paris, 2014.

CAVALCANTE, Leandro Vieira. A nova geografia do coco: reestruturação produtiva, territorialização do capital e dinâmicas socioespaciais. 298 f. Dissertação (Mestrado em Geografia). Universidade Estadual do Ceará, Fortaleza, 2015.

CAVALCANTI, Josefa Salete; MOTA, Dalva Maria; SILVA, Pedro Carlos. Transformações recentes nos espaços da fruticultura do Nordeste do Brasil. In: ELIAS, Denise; PEQUENO, Renato. (Orgs.). Difusão do agronegócio e novas dinâmicas socioespaciais. Fortaleza: Banco do Nordeste, 2006. p. 117-150.

COSTA, José Eloízio da; GEBARA, José Jorge. A cadeia produtiva do coco em Sergipe. In: GERARDI, Lúcia Helena; MENDES, Iandara Alves. (Orgs.). Teoria, técnica, espaços e atividades: temas de Geografia contemporânea. Rio Claro: UNESP, 2001. p. 177-198.

DELGADO, Guilherme. Capital financeiro e agricultura no Brasil. São Paulo: Ícone/ Editora da Unicamp, 1985.

ELIAS, Denise. Globalização e agricultura. São Paulo: EdUSP, 2003.

ELIAS, Denise. Agronegócio e desigualdades socioespaciais. In: ELIAS, Denise; PEQUENO, Renato. (Orgs.). Difusão do agronegócio e novas dinâmicas socioespaciais. Fortaleza: Banco do Nordeste, 2006. p. 25-82.

ELIAS, Denise. O meio técnico-científico-informacional e a reorganização do espaço agrário nacional. In: MARAFON, Cláudio; RUA, João; RIBEIRO, Miguel Ângelo. (Orgs.). Abordagens teórico-metodológicas em Geografia Agrária. Rio de Janeiro: EdUERJ, 2007. p. 49-66.

ELIAS, Denise. Globalização, agricultura e urbanização no Brasil. Acta Geográfica, Boa Vista, v. 1, p. 13-32, 2013.

FONTES, Humberto Rollemberg et al. Sistema de produção para a cultura do coqueiro. Aracaju: Embrapa Tabuleiros Costeiros, 2002.

FREDERICO, Samuel. O novo tempo do Cerrado: expansão dos fronts agrícolas e controle do sistema de armazenamento de grãos. São Paulo: Annablume, 2010.

MARTINE, George. A trajetória da modernização agrícola: a quem beneficia? Lua Nova, São Paulo, n. 33, p. 07-37, 1991.

MARTINS, Carlos Roberto; JESUS JÚNIOR, Luciano Alves de. Evolução da produção de coco no Brasil e o comércio internacional - Panorama 2010. Aracaju: Embrapa Tabuleiros Costeiros, 2011. 
MARTINS, José de Souza. Os camponeses e a política no Brasil. 5. ed. Petrópolis: Editora Vozes, 1995.

MARTINS, José de Souza. A modernidade do "passado" no meio rural. In: BUAINAIN, Antônio Márcio et al. (Orgs.). O mundo rural do Brasil no século 21. A formação de um novo padrão agrário e agrícola. Brasília: Embrapa, 2014. p. 23-31.

MOTA, Dalva Maria et al. O coqueiro (Cocos nucifera L.) em Sergipe: da agricultura de subsistência à coordenação nacional de pesquisa. Aracaju: Embrapa Tabuleiros Costeiros, 1995.

PAULINO, Eliane Tomiasi. Agricultura e tecnificação: notas para um debate. Revista Agrária, São Paulo, n. 4, p. 03-19, 2006.

PEDROSA, Carlos. O colhedor de côcos. Revista Brasileira de Geografia, Rio de Janeiro, v. 9, n. 02, p. 196-198, 1947.

SANTOS, Milton. Metamorfoses do espaço habitado. 3. ed. São Paulo: Hucitec, 1994.

SANTOS, Milton. Técnica, espaço, tempo. 2. ed. São Paulo: Hucitec, 1996.

SANTOS, Milton. Por uma outra globalização. 10. ed. Rio de Janeiro: Record, 2003.

SANTOS, Milton. A natureza do espaço. 4. ed. São Paulo: EdUSP, 2009.

SANTOS, Milton; SILVEIRA, Maria Laura. O Brasil: território e sociedade no início do século XXI. 5. ed. Rio de Janeiro: Record, 2003.

SILVA, José Graziano da. A nova dinâmica da agricultura brasileira. 2. ed. Campinas: Editora da Unicamp, 1998.

SILVA, José Graziano da. Tecnologia e agricultura familiar. 2. ed. Porto Alegre: Editora da UFRGS, 2003.

SIQUEIRA, Luiz Alberto et al. A introdução do coqueiro no Brasil: importância histórica e agronômica. Aracaju: Embrapa Tabuleiros Costeiros, 2002.

LeAndro Vieira CaVAlcante

Graduado e Mestre em Geografia pela Universidade Estadual do Ceará. Mestre em Geografia pela Université Paris 1 Panthéon-Sorbonne. Atualmente é Doutorando em Geografia pela Universidade Estadual do Ceará.

UECE, Programa de Pós-Graduação em Geografia, campus Itapery - Avenida

Silas Munguba, 1700, CEP 60.714.903 - Fortaleza/CE.

E-mail: leandro.cavalcante@hotmail.com 